\title{
Improving prenatal HIV screening with tailored educational interventions: an approach to guideline implementation
}

\author{
B A Prairie, ${ }^{1}$ T Foster $^{2}$
}

${ }^{1}$ Department of Obstetrics, Gynecology and Reproductive Science, University of Pittsburgh, Pittsburgh Pennsylvania, USA ${ }^{2}$ Dartmouth-Hitchcock Medical Center, Lebanon, New Hampshire, USA

\section{Correspondence to} Dr Beth A Prairie, Department of Obstetrics, Gynecology and Reproductive Science, University of Pittsburgh, Magee-Womens Hospital, 300 Halket Street, Pittsburgh, PA 15213, USA

beth.prairie@gmail.com

Accepted 21 March 2010 Published Online First 10 August 2010

\begin{abstract}
Background A healthy, uncomplicated pregnancy undergoes approximately 13 tests performed over an average of 12.5 prenatal visits. Published rates of compliance with routine prenatal testing are generally $>90 \%$, with lower rates for newer tests or those that require additional inputs prior to ordering. New CDC guidelines for prenatal HIV testing highlight the importance of prenatal testing and motivated the authors to explore our routine prenatal testing performance. The authors found the conceptual framework of simple/complicated/ complex problems in healthcare helpful in understanding the rates for tests and for developing interventions.

Methods The setting for this work was a single, rural, academic tertiary care centre. Baseline rates of four routine prenatal tests (HBsAg, $1 \mathrm{~h}$ GTT, GBS, HIV) were determined by analysing 12 months of data from a webbased delivery registry. All rates were $>90 \%$ except HIV, which was $79.2 \%$. Process mapping and discussions with ordering providers were performed to plan the improvement intervention. Targeted educational interventions specific to each ordering provider type were followed by audit and feedback. HIV testing rates were monitored and analysed monthly using process control charts.
\end{abstract}

Results The HIV testing rate increased significantly from $79.2 \%$ to $94.2 \%$. Rates greater than $90 \%$ were maintained for 10 of 11 months reported.

Conclusions Targeted educational interventions combined with audit and feedback can increase rates of routine testing successfully in an outpatient setting. These interventions can be used to improve implementation and compliance with new guidelines when informed by an understanding of local context and processes coupled with an appropriate conceptual framework.

\section{INTRODUCTION}

Prenatal screening in the outpatient setting is a major component of antenatal care. A healthy woman with an uncomplicated pregnancy will undergo approximately 13 tests over an average of 12.5 prenatal visits. ${ }^{1}$ Many tests are performed during the first visit, but others occur at specific gestational ages or are required based on risk. Table 1 illustrates current prenatal tests recommended by the American College of Obstetricians and Gynecologists and the American Academy of Pediatrics in the USA. ${ }^{1}$ Routine tests are required for everyone; optional tests are common and may be recommended but not required.

The Centers for Disease Control and Prevention (CDC) issued new guidelines on HIV screening in the adult population, including recommendations for universal, opt-out screening for prenatal patients. ${ }^{2}$ Establishing the HIV status of pregnant women is important because treatment can reduce vertical transmission to less than $1 \%$ in the first world and significantly reduce maternal morbidity and mortality. ${ }^{3}$ These new guidelines motivated us to determine the reliability of our routine prenatal testing.

The specific aims for this work were: (1) to determine baseline screening rates for routine prenatal tests; (2) to characterise the setting and process of testing; (3) to design, implement and measure the effect of interventions to ensure reliable prenatal testing. Four specific routine prenatal tests (Hepatitis B surface antigen ( $\mathrm{HBsAg}$ ), $1 \mathrm{~h}$ glucose tolerance test (1 h GTT, a screen for gestational diabetes), Group B Streptococcus (GBS) and HIV) were selected because each test represented a different clinic process, and test rates were available in our electronic delivery registry.

\section{METHODS}

This project was submitted to the Dartmouth College/Dartmouth-Hitchcock Committee for the Protection of Human Subjects and determined not to meet criteria for human subjects research (CPHS \# 20995).

\section{Setting}

The setting for this work was a general obstetrical practice team in a single, rural, academic tertiary care centre located in New Hampshire and serving residents of $\mathrm{NH}$ and Vermont. These states generally have good pregnancy outcomes, and most women receive early prenatal care. ${ }^{4}$ The HIV incidence rate in $\mathrm{NH}$ in 2007 was 2.7/100000, compared with a national average of 22.8/100 000 in 2006. ${ }^{6}$ Prenatal care is provided by general obstetrician-gynaecologists (including residents), certified nurse midwives, and maternal-fetal medicine subspecialists. Our work focused on the general obstetric team that cares for about 320 pregnant women per year. The patient population is generally healthy, white and 14\% Medicaid. Patients are assigned to one of four obstetric teams, each consisting of attending physicians, resident physicians, a clinical secretary and an advanced practice nurse (NP).

The presence of the Leadership Preventive Medicine Residency in our institution, with a member of the generalist ob/gyn team also a combined ob-gyn/LPM resident, allowed a unique opportunity to have a dedicated improvement 
Table 1 Recommended routine and optional prenatal tests

\begin{tabular}{|c|c|c|c|c|}
\hline & \multicolumn{4}{|l|}{ Gestational age } \\
\hline & First trimester & $8-20$ weeks & $24-28$ weeks & $32-36$ weeks \\
\hline \multirow[t]{9}{*}{$\begin{array}{l}\text { Routine } \\
\text { tests }\end{array}$} & $\begin{array}{l}\text { Blood type and } \\
\text { antibody screen }\end{array}$ & None & $\begin{array}{l}\text { Screening for } \\
\text { gestational } \\
\text { diabetes }\end{array}$ & $\begin{array}{l}\text { Group B strep } \\
\text { testing }\end{array}$ \\
\hline & $\begin{array}{l}\text { Haemoglobin or } \\
\text { haematocrit }\end{array}$ & & $\begin{array}{l}\text { Haemoglobin or } \\
\text { haematocrit }\end{array}$ & \\
\hline & Urinalysis & & & \\
\hline & Urine culture & & & \\
\hline & Rubella immunity & & & \\
\hline & Syphilis screen & & & \\
\hline & $\begin{array}{l}\text { Chlamydia } \\
\text { screen }\end{array}$ & & & \\
\hline & $\begin{array}{l}\text { Hepatitis B } \\
\text { surface antigen }\end{array}$ & & & \\
\hline & HIV testing & & & \\
\hline \multirow[t]{3}{*}{$\begin{array}{l}\text { Optional } \\
\text { tests }\end{array}$} & $\begin{array}{l}\text { Screening for } \\
\text { trisomies 21, } 18\end{array}$ & $\begin{array}{l}\text { Ultrasound for fetal } \\
\text { morphological } \\
\text { assessment }\end{array}$ & & \\
\hline & $\begin{array}{l}\text { Screening for } \\
\text { cystic fibrosis }\end{array}$ & $\begin{array}{l}\text { Screening for } \\
\text { trisomies 21, } 18 \text { and } \\
\text { spina bifida }\end{array}$ & & \\
\hline & Pap smear & & & \\
\hline
\end{tabular}

champion who was also a provider familiar with the setting. (For more information on this Residency, see Foster et al. ${ }^{7}$ ) This resident was able to both participate in the team and dedicate time to observing and mapping its various functions. ${ }^{7} 8$

Baseline rates of four routine prenatal tests were determined by analysing 12 months of data from our web-based delivery registry. A chart review showed the registry to be $98.2 \%$ accurate. Baseline rates were $>90 \%$ for three of the tests (HBsAg, $1 \mathrm{~h}$ GTT and GBS) but were only $79.2 \%$ for HIV. This suggested that HIV testing differed from other routine prenatal tests, and our third aim was therefore modified to focus on prenatal HIV testing as an opportunity for improvement.

As a first step in investigating this difference, process mapping ${ }^{9}$ was used to learn how, when and by whom prenatal HIV tests were ordered. Process mapping was conducted by a team of four: two front-line providers and two outside observers from a healthcare quality-improvement class. Process maps were generated in MS PowerPoint (Microsoft, Seattle, Washington) and reviewed by all four team members. Both a high-level and a detailed flow chart were generated in order to facilitate understanding of the process and development of targets for intervention. ${ }^{9}$ Process maps were reviewed with multiple stake-holders and revised appropriately. Patients entered prenatal care through one of three possible paths, and HIV testing could be offered at multiple points (see figure 1). We also assessed provider knowledge/attitudes/beliefs via informal conversations regarding prenatal HIV testing. Knowledge gained from these efforts led to planning for an educational intervention. The decision for an educational intervention was based on an apparent lack of provider knowledge about both the guidelines and our performance, as well as the construct of simple, complicated and complex problems. ${ }^{10} 11$ The plan, do, study, act (PDSA) OI cycle framework was used to guide planning and implantation. ${ }^{12}$

We believed that HIV testing was unlike other prenatal tests in our setting. Liu et $a l^{10}$ have applied Glouberman and Zimmerman's ${ }^{11}$ framing of problems as simple, complicated or complex to an inpatient care setting. We found this model

Figure 1 HIV ordering process.

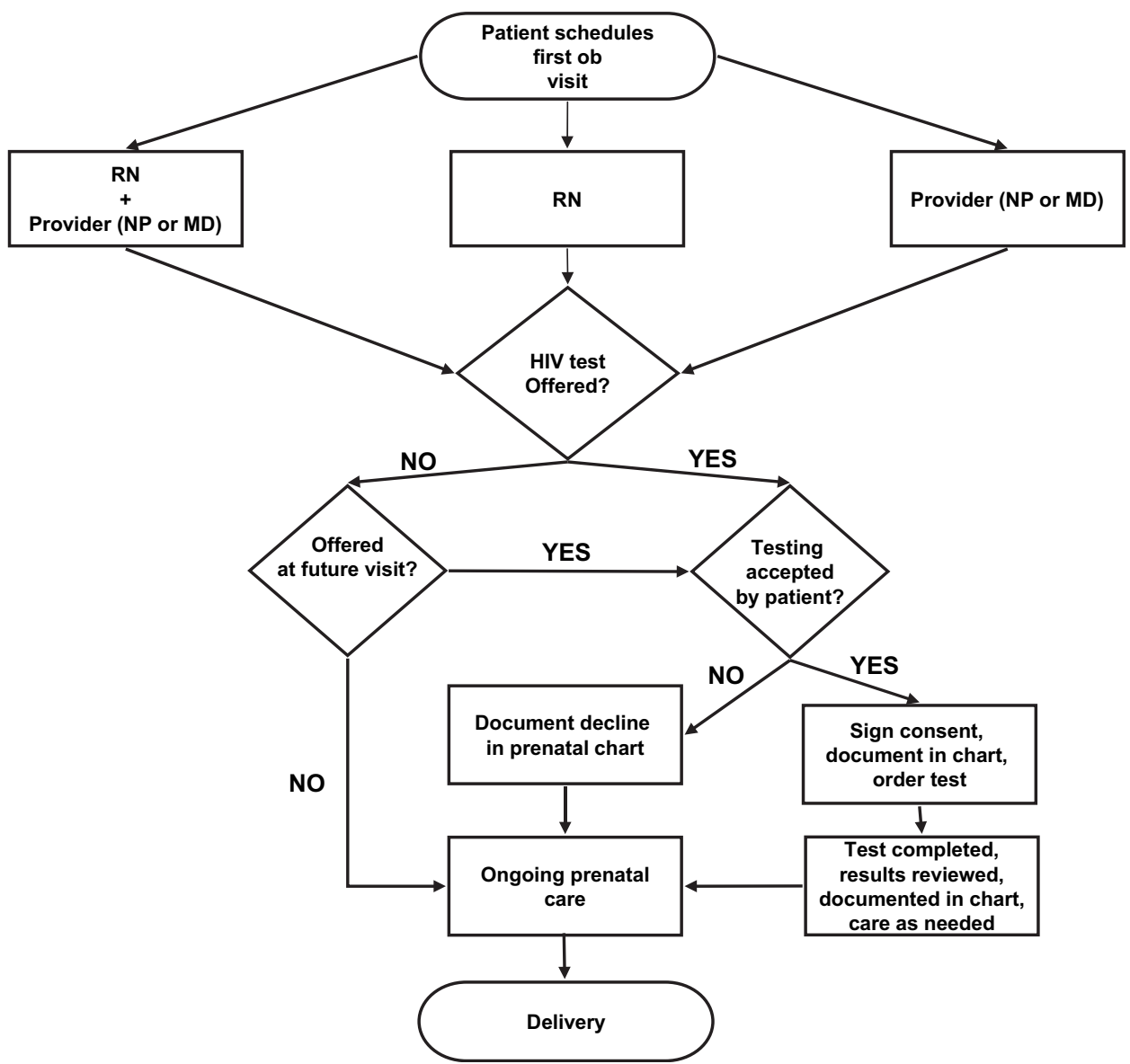


Table 2 Glouberman and Zimmerman's model of simple, complicated and complex (adapted with permission from Liu et al ${ }^{10}$ )

\begin{tabular}{|c|c|c|c|}
\hline & Simple & Complicated & Complex \\
\hline \multicolumn{4}{|l|}{ Example task } \\
\hline Non-clinical & Baking a cake & Sending a rocket to the moon & Raising a child \\
\hline Clinical & Screening for a urinary tract infection & Screening for gestational diabetes & Screening for HIV \\
\hline Process & Recipe or set of instructions is necessary & $\begin{array}{l}\text { Formulae are critical and necessary for } \\
\text { success }\end{array}$ & $\begin{array}{l}\text { Formulae and recommendations are } \\
\text { useful but limited in application }\end{array}$ \\
\hline Expertise required & $\begin{array}{l}\text { None, but previous experience can } \\
\text { improve success }\end{array}$ & $\begin{array}{l}\text { High levels of expertise and specialised } \\
\text { coordination of resources are necessary }\end{array}$ & $\begin{array}{l}\text { Expertise can contribute but is not } \\
\text { necessary or sufficient to ensure success }\end{array}$ \\
\hline Uniqueness of outcome & $\begin{array}{l}\text { A good recipe produces the same result } \\
\text { every time }\end{array}$ & $\begin{array}{l}\text { Following the formulae should ensure } \\
\text { similar outcomes }\end{array}$ & Each outcome is unique \\
\hline Expected outcome & The same result every time & $\begin{array}{l}\text { High degree of certainty of outcome if } \\
\text { formulae are followed correctly }\end{array}$ & $\begin{array}{l}\text { Outcome is uncertain and cannot be } \\
\text { reliably predicted beforehand }\end{array}$ \\
\hline
\end{tabular}

helpful for understanding why HIV testing was different and for developing appropriate interventions. Table 2 describes this model, with examples of its application in our setting.

HIV testing represented a complex process: patient and provider beliefs influence testing, there is potential associated stigma, and the clinic process included additional steps not required for any other tests. Complex problems are best addressed when patients' and providers' aims are shared and explicit. A complex process such as HIV testing would not be amenable to solutions such as checklists or algorithms but would require a multifaceted approach accounting for dynamic process relationships.

\section{Choosing the intervention}

Passive education alone may increase awareness, but most studies show this does not translate into a change in practice or behaviour for obstetric providers. ${ }^{13-15}$ Continuing medical education conferences also have little effect on practice. ${ }^{16}$ However, education used as one component of a multifaceted intervention may be effective in changing behaviour. ${ }^{17} 18$

Process analysis demonstrated that the three different provider groups for the general obstetric team (attending physicians, residents and advanced practice nurses) differed in their practices and attitudes. Therefore, the content and context for the planned educational interventions were customised. Residents received a didactic lecture followed by role play and discussion; nurse practitioners received an informational hand-out with an informal discussion using modified consensus process; attending physicians were visited for one-on-one conversations.

These educational sessions were also used to prepare for the next step: team-level audit and feedback of HIV testing performance. Interactive discussions about the frequency and nature of feedback to maximise utility were undertaken. We prepared a data wall in the clinic and held regular meetings with each team. Teaching teams to seek feedback, and incorporating knowledge about testing into the team function, was included to address sustainability. Educational sessions were held from March through October of 2007; audit and feedback began in October 2007. Table 3 reviews the various interventions, underlying rationale and timeline of implementation.

\section{Measures and analysis}

The primary outcome for this intervention was the percentage of generalist patients who received a prenatal HIV test prior to admission for delivery. At the time of admission for delivery, information about the pregnancy, including prenatal testing, is entered into a web-based delivery registry (OBNet, OBNet Services LLC). Monthly reports were generated from the registry. A data analysis was performed monthly using Microsoft Excel to generate control charts of testing rates for prenatal labs. Statistical process control charts were used given the ongoing nature of the improvement work and the ability to characterise variation in the process. ${ }^{19}$ This also allowed ongoing monitoring. $\mathrm{P}$ charts were reviewed monthly for special cause signals, indicating a significant change in the process beyond normal variation, and standard rules were used to identify special cause signals. $^{20}$ The analysis presented here is from March 2007 to June 2008 .

\section{RESULTS}

HIV screening rates are shown in figure 2 . The HIV testing rate increased significantly from $79.2 \%$ to $94.2 \%$ with rates greater than $90 \%$ maintained for the 10 of 11 months reported. Continuing high screening rates suggest this intervention successfully built in sustainability. There were no new diagnoses of HIV and no positive tests. No significant changes were seen in the rates of Hep B, $1 \mathrm{~h}$ GTT or GBS tests tracked during the study period. The control chart was split when the special cause

Table 3 Summary of improvement interventions

\begin{tabular}{|c|c|c|c|c|c|}
\hline \multicolumn{3}{|c|}{ Start date End date Intervention/action } & \multirow{2}{*}{$\begin{array}{l}\text { Rationale } \\
\text { Understand current processes }\end{array}$} & \multirow{2}{*}{$\begin{array}{l}\text { Planned measure } \\
\text { Able to construct process map }\end{array}$} & \multirow{2}{*}{$\begin{array}{l}\text { Outcome } \\
\text { Process map completed }\end{array}$} \\
\hline $11 / 06$ & $8 / 07$ & Characterise setting & & & \\
\hline $3 / 07$ & $3 / 07$ & $\begin{array}{l}\text { Resident education: mixed didactic } \\
\text { slide lecture with role play }\end{array}$ & $\begin{array}{l}\text { Receive weekly didactic lectures; } \\
\text { active component to learning improves } \\
\text { retention }\end{array}$ & HIV screening rates & Increased rates \\
\hline $3 / 07$ & $10 / 07$ & Determine baseline testing rates & Understand current performance & $\begin{array}{l}\text { Rates of hepatitis B virus, gestational } \\
\text { diabetes, group B streptococcus, HIV } \\
\text { screening }\end{array}$ & Known rates over 12 months \\
\hline $3 / 07$ & $10 / 07$ & $\begin{array}{l}\text { Attending education: informal individual } \\
\text { conversations }\end{array}$ & $\begin{array}{l}\text { Unaccustomed to formal interventions } \\
\text { in clinical care }\end{array}$ & HIV screening rates & Increased rates \\
\hline $4 / 07$ & $4 / 07$ & $\begin{array}{l}\text { Nurse practitioner education: handout, } \\
\text { modified consensus process }\end{array}$ & $\begin{array}{l}\text { Hold regular small group meetings; } \\
\text { accustomed to modified consensus } \\
\text { process }\end{array}$ & HIV screening rates & Increased rates \\
\hline $10 / 07$ & Ongoing & Audit and feedback & $\begin{array}{l}\text { Knowledge of performance supports } \\
\text { improvement efforts }\end{array}$ & HIV screening rates & Increased rates \\
\hline
\end{tabular}


Figure 2 P-chart of monthly HIV tests from April 2006 to June 2008.

\section{Percent of all generalist team patients with completed HIV tests}

Begin

Intervention

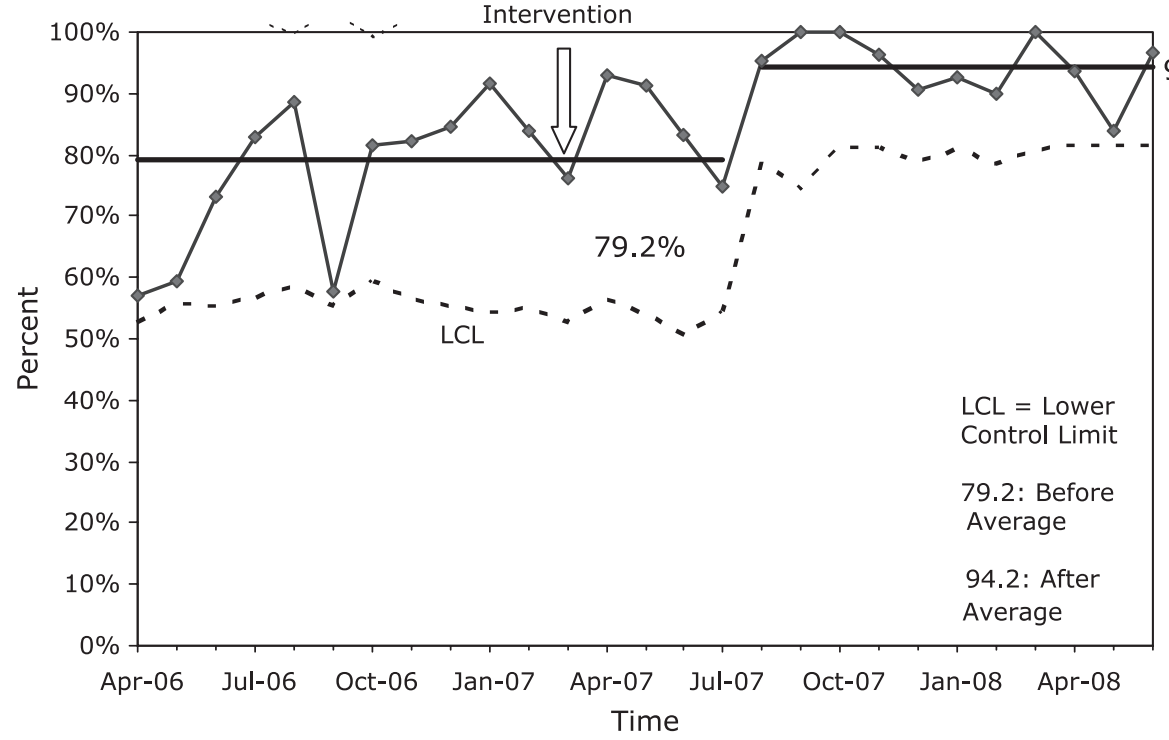
$94.2 \%$

signal of eight consecutive data points above the centre line was achieved.

The educational intervention and audit and feedback process proceeded on schedule with no major changes from the planned intervention. The interventions were generally well received, though buy-in varied, with two teams becoming very engaged and two teams being only somewhat engaged. Very engaged teams began their own process improvement initiatives for prenatal testing and requested additional coaching. Somewhat engaged teams participated but did not initiate their own changes or request additional coaching.

No changes in the care process were planned as part of this intervention. However, there was a change in the state law during the intervention. This change eliminated a separate consent form, and changed the consent standard from 'informed consent' to 'consent' for HIV testing as of October 2007. The increased rates began after the educational intervention but before the change in state law.

\section{DISCUSSION}

We have presented an integrated, multimodal approach to significantly increasing prenatal HIV screening in an outpatient, general ob/gyn setting. Our approach to this problem began with work to develop a deep understanding of the local context, identifying a theoretical framework for project planning, and then implementing tailored educational interventions combined with team-level audit and feedback for sustainable improvement.

Mapping the process for ordering the four selected prenatal tests led us to question the nature of the differences between the tests. Glouberman and Zimmerman's construct of the simple, complicated and complex in healthcare, further elaborated by Liu et al, fit with our documented clinic processes. ${ }^{10}{ }^{11}$ Tests that had the highest rates met the definition of simple processes; HIV testing represents a complex process. Understanding the nature of HIV testing and what made it different allowed us to proceed with a multifaceted approach to change, matching the nature of the problem to the nature of the intervention.

Limitations in this work include the inability to track the effect of the change in consent documentation on the measured outcome, as well as the anticipated lack of impact on patient outcomes regarding HIV. Given low sero-prevalence, it is unclear on a population level what the real impact of improved adherence to the CDC guidelines will be. While the results have been sustained over nearly a year, how well they will be sustained further into the future is unknown. Finally, patients retain the autonomy to opt-out of HIV screening, and rates at which patients declined testing were not explicitly evaluated.

Sustainability was built in to this effort. In an academic setting where care is provided by residents who change every few years, long-term change must be implemented in robust systems that withstand staff turnover. Routine data collection, analysis and posting were made a part of the nurses' duties, and feedback to providers was performed monthly. Supervising attending physicians oversee all care without the frequent turnover of residents.

Practically, this intervention demonstrates an inexpensive way to improve routine testing performance using evidence-based improvement strategies in conjunction with an appropriate conceptual framework. While HIV testing presents some unique challenges, the general approach of process mapping, assessing knowledge/attitudes/beliefs and implementing tailored educational interventions supported by audit and feedback applies to many outpatient testing contexts. Although there is an extensive literature documenting lower-than-desired prenatal HIV testing rates in the USA and Canada, there is an apparent dearth of practical approaches for remedying that on a clinical level. The

\section{Key messages}

- A deep understanding of the local context, coupled with a theoretical framework, was the basis for designing successful improvement interventions.

- Participatory educational interventions targeted to specific audiences and combined with audit and feedback produced a significant increase in our HIV testing rates.

- In our setting, HIV testing represented a complex process, requiring interventions that account for dynamic relationships and are flexible and multifaceted. 


\section{Educational points}

- Process mapping is an essential step in designing and planning improvement interventions.

- Introducing regular, scheduled feedback to a new group can improve buy-in from key stakeholders.

- Using a theoretical framework provides structure and rationale for matching an intervention to a process or problem.

testing rates reported here, generally in the 95\% range, are consistent with other reports ${ }^{21-23}$ and beg the question of reliable systems in healthcare. Amalberti et al outlined the current state of healthcare reliability and identified major barriers to highly reliable patient care systems. ${ }^{24}$ This work represents only the first step in improving reliability. The next step involves utilising a different set of tools, those needed to propel us from reliable to highly reliable, or from good to great.

Acknowledgements The Dartmouth-Hitchcock Leadership Preventive Residency provided the time of one resident to work on this project.

Competing interests None.

Provenance and peer review Commissioned; externally peer reviewed.

\section{REFERENCES}

1. American Academy of Pediatrics and American College of Obstetricians and Gynecologists. Guidelines for perinatal care. 6th edn. Washington, DC: ACOG, 2007:99-108

2. Branson BM, Handsfield HH, Lampe MA. Revised recommendations for HIV testing of adults, adolescents, and pregnant women in health-care settings. MMWR Recomm Rep 2006;55[No. RR-14]:1-17.

3. Chou R, Smits A, Huffman L, et al. Screening for human immunodeficiency virus in pregnant women: systematic evidence synthesis. Prepared for: Agency for Healthcare Research and Quality, US Department of Health and Human Services. 2005. http://www.ahrq.gov/downloads/pub/prevent/pdfser/hivpresyn.pdf (accessed 6 Jan 2010).

4. National Center for Health Statistics. Health, United States, 2008 with chartbook. Hyattsville, MD: CDC 2009. Tables 8, 14, 22 \& 23. http://www.cdc.gov/nchs/data/ hus/hus08.pdf (accessed Jan 2010).

5. New Hampshire Department of Health \& Human Services. Division of Public Health Services, Communicable Disease Surveillance Section. New Hampshire STD/HIV/
AIDS Surveillance Summary Report 2003-2007. http://www.dhhs.state.nh.us/DHHS/ CDCS/LIBRARY/Data-Statistical + Report/hiv-aids-report.htm (accessed 6 Jan 2010).

6. Hall HI, Song R, Rhodes $P$, et al. Estimation of HIV incidence in the United States. JAMA 2008:300:520-9.

7. Foster $\mathbf{T}$, Regan-Smith M, Murray $C$, et al. Residency education, preventive medicine, and population health care improvement: the Dartmouth-Hitchcock leadership preventive medicine approach. Acad Med 2008;83:390-8.

8. Fitzpatrick DL, George KE, Foster T, et al. A resident rotation in practice-based learning and improvement and systems-based practice: making meaningful improvements in patient care. Presented at ACGME annual educational conference, Grapevine, TX, Mar 2009.

9. Nelson EC, Batalden PB, Godfrey MM. Quality by design: a clinical microsystems approach. San Francisco: Jossey-Bass, 2007. p 297-300.

10. Liu SK, Homa K, Butterly J, et al. Improving the simple, complicated, and complex realities of community-acquired pneumonia. Qual Saf Health Care 2009;18:93-8.

11. Glouberman S, Zimmerman B. Complicated and complex systems: What would successful reform of medicine look like? In: Forest PG, Mckintosh T, Marchilden G. eds. Health care services and the process of change. Toronto: Univ of Toronto Pr, 2004.

12. Nelson EC, Batalden PB, Godfrey MM. Quality by design: a clinical microsystems approach. San Francisco: Jossey-Bass, 2007. p 271-81.

13. Lomas J. Words without action? The production, dissemination, and impact of consensus recommendations. Annu Rev Public Health 1991;12:41-65.

14. Foy R, Crilly M. Evidence-based reproductive health care: getting evidence into practice. J Fam Plann Reprod Health Care 2004;30:17-20.

15. Davies B, Hodnett E, Hannah M, et al. Foetal health surveillance: a community-wide approach versus a tailored intervention for the implementation of clinical practice guidelines. CMAJ 2002;167:469-74.

16. Davis DA, Taylor-Vaisey A. Translating guidelines into clinical practice. A systematic review of theoretical concepts, practical experience and research evidence in the adoption of clinical practice guidelines. Can Med Assoc J 1995;157:408-16.

17. Leviton LC, Goldenberg RL, Baker CS, et al. Methods to encourage the use of antenatal corticosteroid therapy for fetal maturation: a randomized controlled trial. JAMA 1999;281:46-52.

18. Poma PA. Effect of departmental policies on cesarean delivery rates: a community hospital experience. Obstet Gynecol 1998;91:1013-18.

19. Nelson EC, Batalden PB, Godfrey MM. Quality by design: a clinical microsystems approach. San Francisco: Jossey-Bass, 2007. p 350-61.

20. Nelson EC, Batalden PB, Godfrey MM. Quality by design: a clinical microsystems approach. San Francisco: Jossey-Bass, 2007. p 354-5.

21. Sheikh LA, Sarnquist C, Grieb EM, et al. Prenatal screening for infectious diseases: an analysis of disparities and adherence to policy in California. Matern Child Health $J$ 2008;13:260-7.

22. Bascom S, Miller S, Greenblatt J. Assessment of perinatal hepatitis B and rubella prevention in New Hampshire delivery hospitals. Pediatrics 2005;115:594-9.

23. Schrag SJ, Arnold KE, Mohle-Boetani JC, et al. Prenatal screening for infectious diseases and opportunities for prevention. Obstet Gynecol 2003:102:753-60.

24. Amalberti R, Auroy $Y$, Berwick $D$, et al. Five system barriers to achieving ultrasafe healthcare. Ann Intern Med 2005:142:756-64. 